\title{
Personality Particularities of Adolescent Probationers under Conditions of Preventive Measures Against Repetitions of Crime
}

Tatiana Rodermel

Surgut State University, Russia, 628412, 1 Lenina Str., Surgut, KhMAD-Yugra, Tyumen Region

Maya Samoilova

Surgut State University, Russia, 628412, 1 Lenina Str., Surgut, KhMAD-Yugra, Tyumen Region

Tatiana Mamkina

Surgut State University, Russia, 628412, 1 Lenina Str., Surgut, KhMAD-Yugra, Tyumen Region

Natalia Hohlova

Surgut State University, Russia, 628412, 1 Lenina Str., Surgut, KhMAD-Yugra, Tyumen Region

\author{
Doi:10.5901/mjss.2015.v6n6s5p146
}

\section{Abstract}

The paper deals with studying the personal particularities of adolescent probationers as well as with describing the specific character of social and psychological support of such adolescents in order to prevent recurrent crimes. As determined by us, the address object of this paper is a socially neglected adolescent. The character of such minors is formed, as a rule, under the influence of asocial and criminogenic groups. The groups are distinguished by a high extent of perceiving the distortion and destruction of values related to legal sphere, as well as by antisocial behavior and wrongdoings (vagrancy, drugs abuse, drinking, extortion). Such teenagers as a rule have no goal setting in relation to the professional sphere, they are not oriented to work - they have a negative attitude to it and are set to parasitic way of life. The paper presents an experience of using the project form of work in the sequence of which the dynamics of personal development of the ones in ward is outlined. The authors emphasize the fact that psychological support of adolescent probationers has to be performed not only in the direction of preventing the delinquent behavior but also toward the process of their re-socialization. The work is aimed at studying the personal particularities of adolescent probationers.

Keywords: repetition of crime, inmates, "criminal" dependence, mental health, psychological support of a convict, conflict.

\section{Introduction}

In today's society, the problem of increasing scale of recurrent crimes committed by minors is gaining especial relevance. According to criminal statistics data, $19 \%$ to $45 \%$ of former students of juvenile correctional facilities and $50 \%$ of graduates of special schools for minors commit repeated crimes within the first three years after exiting the institutions. The statistics show that every seventh of ten crimes is committed by minor ex-inmates (Gerasimov, 2002; Blackburn, 2002; Moffitt et al., 2002).

The most frequent causes of recurrent crimes prove to be unresolved social problems (lack of permanent accommodation, means for simplest daily life things, food, lack of documents, job, relatives who would be ready to accept them and help them etc.) which the minors face after being released (Lukin, 1993; Dementieva, 2000; Zmanovskaya, 2003; Alekseeva, 1997; Washburn et al., 2007).

The basis for repeated crime can also become unfavorable situation in the family as of the minor's release, conflict relationships with the family members. The point is that the majority of ones returning from special institutions are children of socially disadvantaged families having a low pedagogical culture and no wish for improving that.

Social preventive work carried out with minors returning from places of detention consists in "rehabilitation" and transformation of the social micro-environment. Formation of the minors' readiness to the most efficient adaptation is ensured by creating an integrated system of social-psychological work with them which enables them to be re-included 
into the socium (Sotsialnaya profilaktika pravonarusheniy, 1990; Levitt et al., 1993; Moffitt et al., 2002).

We believe that it is the problem of studying the personality of adolescents who got criminal conviction and served sentence under various forms of punishment that can be relevant as of today. The minors whose behavior has destructive character are distinguished by a high frustration level and are not always sensible in estimating the events around them (Bandura, 2000; Blum, 1994). They opt for the easiest in their opinion way to achieve life goods, namely, committing a crime, and explain it by envy or by wish of thrill. Moreover, relying on works by V.B. Khoziev, E.V. Zmanovskaya and others, we associate such behavior with the problems of mental health of the adolescents, with them developing stable asocial habits and, as a consequence, with disorders of character - in particular, with emergence of accentuations which risk having a dynamics towards psychopathies (Khoziev, 2005).

The practical activity of socionomics specialists of social service rehabilitation institutions shows that the law breaking minors after committing a delinquent (antisocial) deed are consequently placed in State special childcare institutions.

Thus, the main rehabilitation component in these institutions becomes tertiary preventive care aimed at preventing the repeated committing of the delict in adolescent probationers. Regrettably, statistics show that the greater part of the adolescents commit crimes again. This fact gives evidence of the "criminal" dependence of minors' personality increasing with time, and this directly depends on various aspects of personality development. Proceeding from this, we believe the basic direction in socionomics specialist work has to be organizing and carrying out the systemically structured psychological support of the convicts.

Our research began with studying the forms of behavior in adolescent convicts who were oriented to neutralization of the conflict. Next, in order to eliminate individual-personal and group tension, a number of exercises were performed. The participants were adolescents aged 14 to 21 (22 convicts not sentenced to imprisonment). The research was conducted during six months in 2011 on the basis of "Social security militia" of Surgut.

Further work on preventing the repeated crimes was performed on the basis of Special custodial type comprehensive school. 7 adolescent probationers (aged 15 to 17) having a high level of "criminal contamination" took part in the research (Gerasimov, 2002).

Within the preventive work countering the repeated crimes, the work was distributed into four stages: the first one was diagnostic, the second involved developing a course based on the personal particularities revealed and the specific features of punishment measure for the adolescents. The third stage included preventive measures, and the fourth one represents analysis and generalization of the results obtained (Akopov et al., 1998).

\section{Techniques, Results and Stages of the Research}

Our research was aimed at studying the individual personality characteristics of the adolescents as well as social situation of their development. To carry out the diagnostic study, we used such techniques as: S. Rosenzweig test revealing the main highlights of the life story of the adolescent convict and crime committed by him; a modified selfassessment diagnostics technique by T. Dembo - S.G. Yakobson; an individual and typological questionnaire (L.N. Sobchik). L.N. Sobchik's technique was used for revealing the leading trends determining the individual type of emotion, strength and direction of motivation, the style of interpersonal communication and the content of cognitive processes, as well as the presence of accentuated character traits in the tested ones (Braht, 1994; Gerasimov, 2002).

In combination with the listed techniques, clinical group interviews of adolescent probationers was carried out which found a high "criminal contamination" level in them. The range of crimes committed by them was revealed (stealth, extortion, vagrancy, alcohol abuse, car theft, fighting, damage to others' property, drugs abuse, toxic substances addiction). During additional studies using medical and psychiatric expertise, a psychiatric diagnosis was made: $57 \%$ of the preventing course participants had behavior disorders.

The results obtained using T. Dembo - S.G. Yakobson's technique have shown a high or unstable self-assessment level (in $63 \%$ of all participants of the course). When working on revealing their self-assessment, the adolescents had difficulty delivering a detailed and logical answer; a low reflexion development level was registered. This manifested itself in inability to analyze their own deeds, lack of critical evaluation of their own deeds, for example, in such adolescents' answers as "Everybody does so", "Just like everyone" etc.

L.N. Sobchik's questionnaire has allowed us to find out the individual and personal adolescent character traits and the extent thereof which are common for the group. The results of study have demonstrated a high level of aggression and auto-aggression, negativism in evaluating the opinions of other people, pessimism in assessing the life prospects, motivational and emotional instability, an increased need of expanding the range of contacts and consolidating one's authority among the peers, and the lack and frequent irrelevance of communication means (Individual and typological 
questionnaire of L.N. Sobchik).

The result of S. Rosenzweig's test (Lukin, Suvorov, 1993) and L.N. Sobchik's questionnaire was the index of conflict behavior strategy. With the tested ones, the main strategy is rivalry - this is stated in $50 \%$ of the course participants. The parameters of general culture (foul language, improper actions toward others' personal belongings), reflexion (inability to control one's behavior, abandonment) had a low level in the adolescents. Disrespectful attitude to the controlling staff was found. During further work in clinical interviews, the notion of "family" was discussed which proved to be very relevant and significant for them. During the clinical interviews a reverent attitude of the adolescents to members of their families was revealed. We watched it in their emotional state changing - from markedly indifferent to dreamy, from love to frank negativism.

Thus, the research has shown that the crimes committed are a manifestation of an adolescent's conflict with the socium and with himself.

Next, we moved on to the second stage of work with the adolescents which implied creating and bringing into life a program of prevention of their proneness to conflict. The analysis of social-psychological support programs available for adolescents having a punishment measure has demonstrated the discrete nature of problems being solved, eclectic approach to using the problem situations resolution techniques and means, lack of procedure for forming the joint activity means and so on (Bandura, 2000). Another form of work had to be looked for and the system of means for adolescents to organize and plan their own life had to be unfolded in the new logic. We developed a project "Conflicts in our life" (Ghilinskiy, 1993; Khoziev et al., 2014) within which the important for this age and life period interests of adolescents and the interaction organization problems for small groups were considered.

At the third stage of the research, the personal development dynamics of the project class participants was the subject of study. The project classes were given at the special school in 2010-2011. Let us describe the results obtained when studying the process of adolescents' inclusion into work in the most detailed way. Let us look at the probationers' dynamic having broken it down into 3 stages as follows.

1) classes 1 - 7: the adolescents mastered the means of communication, cooperation and acceptance of themselves. At the first class, a low level of the indices was registered as the wards are not adaptive enough in the conditions of a special school. Over half of the participants demonstrated negativism and aggression, but the adolescents started to get gradually involved into the project so early as from the second class on. The minors mastered the interaction means step by step and joined the new forms of work: discussion of situations in pairs, joint making of collages, planning of their own life prospects.

Table 1. Input data results (the number means that of the program participant)

\begin{tabular}{|c|l|l|c|}
\hline \multirow{2}{*}{ No. } & Level & T. Dembo - S.G. Yakobson's technique \\
\cline { 2 - 4 } & S. Rosenzweig's test & L.N. Sobchik's questionnaire & Behavior strategy \\
\hline 1 & high aggression and auto-aggression & high proneness to conflict & rivalry \\
\hline 2 & high aggression and auto-aggression & negativism in evaluating the others' opinions & conformism \\
\hline 3 & pessimistic evaluation of life prospects & negativism in evaluating the others' opinions & avoidance \\
\hline 4 & high aggression and auto-aggression & high proneness to conflict & rivalry \\
\hline 5 & pessimistic evaluation of life prospects & negativism in evaluating the others' opinions & avoidance \\
\hline 6 & high aggression and auto-aggression & high proneness to conflict & rivalry \\
\hline 7 & pessimistic evaluation of life prospects & negativism in evaluating the others' opinions & avoidance \\
\hline 8 & high aggression and auto-aggression & high proneness to conflict & rivalry \\
\hline
\end{tabular}

The following findings were used as summary.

Table 2. Comparative indices of the diagnostic study

\begin{tabular}{|c|c|c|c|c|c|c|c|}
\hline \multirow[t]{2}{*}{ Level } & \multicolumn{2}{|c|}{$\begin{array}{l}\text { S. Rosenzweig's } \\
\text { test }\end{array}$} & \multicolumn{2}{|c|}{$\begin{array}{l}\text { L.N. Sobchik's } \\
\text { questionnaire }\end{array}$} & \multirow[t]{2}{*}{$\begin{array}{l}\text { Behavior } \\
\text { strategy }\end{array}$} & \multicolumn{2}{|c|}{$\begin{array}{c}\text { T. Dembo- } \\
\text { S.G. Yakobson's technique }\end{array}$} \\
\hline & Input \% & Final $\%$ & Input \% & Final \% & & Input \% & Final \% \\
\hline High aggression & 62,58 & 70 & 50 & 60 & rivalry & 50 & 37 \\
\hline \multirow[t]{3}{*}{ Low aggression (negativism to each other) } & 37,5 & 30 & 50 & 40 & avoidance & 37,5 & 25 \\
\hline & & & & & conformism & 12,5 & 10 \\
\hline & & & & & cooperation & - & 28 \\
\hline
\end{tabular}


2) classes $8-12$ were the period of relative stability. Higher activity was pointed out in the work of adolescents, as well as their interest in events taking place, their degree of trust to the psychologist and the group. The transition of working "side by side" to elements of joint activity was stated with the adolescents, which promoted a positive change in relationships. At this stage, the factors preventing the mastery of communication ways were eliminated in part. The process of realizing the constructive conflict situations behavior strategies began.

Table 3. Dynamics in interaction with peers

\begin{tabular}{|c|c|c|c|c|c|c|c|c|}
\hline No. & 1 & 2 & 3 & 4 & 5 & 6 & 7 & 8 \\
\hline 1 & & + & & & & & & \\
\hline 2 & & & & + & & & & \\
\hline 3 & & & & & + & & & \\
\hline 4 & & & + & & & & & \\
\hline 5 & & & & & & + & & \\
\hline 6 & & & & & & & & \\
\hline 7 & & & & & & & & + \\
\hline 8 & & & & & & & & \\
\hline
\end{tabular}

As we see, No. 8, 7, 1, 6 have got a zero status and do not choose anyone. Other adolescents have a not very positive situation within the interaction too. No-one chooses each other mutually and not all of them show any interest in each other.

By class 12, it had been as follows.

Table 4. Final indices of mutual choices of the program participants

\begin{tabular}{|c|c|c|c|c|c|c|c|c|}
\hline No. & 1 & 2 & 3 & 4 & 5 & 6 & 7 & 8 \\
\hline 1 & & + & & & & & & \\
\hline 2 & + & & & + & & & & \\
\hline 3 & & & & & + & & & \\
\hline 4 & & & + & & & & & \\
\hline 5 & & & & & & + & & \\
\hline 6 & & & & & & & + & \\
\hline 7 & & & & + & & & & + \\
\hline 8 & & & & & & & + & \\
\hline
\end{tabular}

We paid attention to mutual interests emerging among the minors and there already were no participants having a zero status!

3) classes $13-15$ were the stage of using the means mastered in conditions of solving a new task. At these classes, the adolescents had to prepare a speech on a set topic "What has changed in me", "My picture of the future" etc. independently. The presentations were prepared almost with no help from the psychologist who led the project. The adolescents wanted to surprise the psychologist and other teachers, their peers and to demonstrate what they had learned at the project.

Here is an example - the presentation by Petya K.:

"I see the goal of my future in employment. I want to study at a college and to become a metal worker. Then I will work where they take me, I will get some experience and go on to work in a division of Surgutneftegaz. And after that, one can have a family...".

The orientations unfolded along a path from non-differentiated, amorphous understanding of various aspects of social psychology to a more and more differentiated and conscious one. A bright example confirming the fact of adolescents having maximum unfolded orientation in social interaction means during their solving of various project tasks was the presentation prepared by them at the last class, the fifteenth one (Khoziev et al., 2014). The adolescents showed their knowledge and abilities of finding a way out of conflict situations. Moreover, they learned to work as a team, to be tactful and attentive to their peers when doing joint tasks. This is why we view a positive dynamics (reduced quantity of manifestations) of such parameters as aggressiveness and hostility (Figure 1). Before the classes, with $62.5 \%$ of the 
wards a high aggression level had been found, and a high proneness to conflict level - with $50 \%$ of the wards, while after the course the proportion was $12.5 \%$ and $12.5 \%$, respectively. The results differ statistically validly according to Student's test at $p \leq 0,001$.

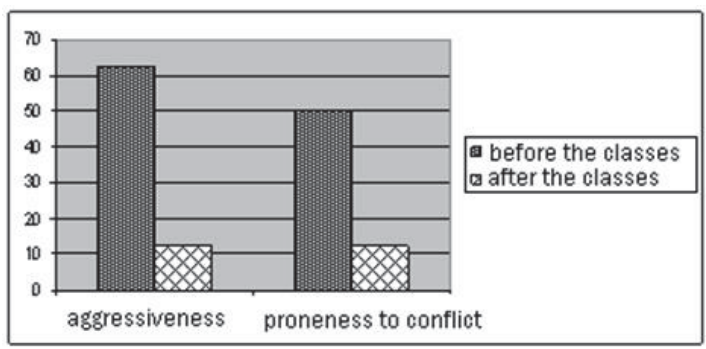

Figure 1. Change of aggressiveness and hostility parameters level in adolescents before and after the classes

\section{Discussion of the Research Results}

After the project completion, repeated diagnostics was performed with the techniques used in pre-testing. The findings have shown that in all adolescents the pathological character features diagnosed previously were closer to the boundaries of the "norm". It has to be pointed out that although the aggressive reactions in the group participants were not eliminated completely during the project work, they were yet considerably reduced. We have registered the medium aggression level in the adolescents, as compared to the high one before the project. And this is normal, given the duration of the previous negative life experience of the adolescents and their brief stay in the project. In activities which are more habitual for them, e.g. while cleaning a room, participating in usual events etc., aggression has begun to be manifested to a much smaller extent than before taking part in the project: the rude and obscene addresses, aggressive intonation while addressing somebody have disappeared, and so have non-constructive physical ways of pressure on peers etc.

Similar change has been found in evaluating oneself on the part of others; possibly, this confirms the adolescents passing to an essentially higher level of decentration, the development of self-control, and transition to the level of verbal explanation of grounds for self-assessment. Another achievement of the project was its participants' accepting the means for adjusting their autogenic condition which later were used outside the classes. Autogenic training has helped the wards to emotionally unload and stabilize their mental and physical load in stress situations and in ones of emotional exhaustion and tiredness.

The emergence (in some adolescents) and increase (in others) of the level of criticism in evaluating various opinions was quite valuable. Pessimism which was characteristic for the project participants went down and they started to use more objective grounds when estimating the future and to have realistic life goals. A very important personal change can also be named the developed tolerance to failures and unsuccessfulness of both peers and adults around them. The new experience obtained during communication within the project enabled the adolescents to become more stabilized in what concerns emotions and motivation.

At the fourth, final stage of supporting the adolescent probationers, individual psychological counseling was organized which became a kind of psychological preliminary instruction for life prospects. This work allowed consolidating the knowledge obtained and developing a life strategy for the nearest future for most of the adolescents.

\section{Conclusion}

The scientific and practical work conducted has demonstrated that psychological support for adolescent probationers has to be performed not only for preventing the delinquent behavior but also for providing the process of their re-socialization, support in development of personal and age-related new formations.

Certainly, some shortcomings associated both with individual particularities of the adolescents and the characteristics of the group on the whole were noted in performance of the research program. Some minors (ones who refused to take part in the project work or to get individual psychological counseling) got repeated conviction (6 adolescents) and part of them (9 people) got extended conviction due to repeated delict before expiry of the probation. 
After working with the minors, another half a year's observance of them was performed which has shown positive personal change. The most prominent one was adherence to regulations: for a relatively prolonged period the adolescents got no reprimands and were not noticed by the ones in charge of the special institutions to break the regime and discipline (Melnikova, 1966).

Therefore, the practical implementation of the above situation with wrongdoings among minors requires special conditions for organizing social-psychological and pedagogical developing playing technologies in correctional work with minors which can also be applied as preventive measures for deviant behavior.

A positive resonance from the work consists in normalizing the process of interpersonal communication and success in learning as a developing effect in the cognitive sphere (Rodermel, 2014). When studying the conditions promoting the formation of personality of minors, we have proved that aggressiveness is the culmination of conflicts escalating from the early childhood. Alongside with this, we have paid attention to the phenomenon of behavior destruction which is a personality's defense in the ability to close or to overcome obstacles. Interactions with various people increase or reduce the tension of the entire system and promote overcoming or avoiding the conflict, lead to mutual satisfaction.

The adaptation processes themselves cause tension in the personal relationships system and are no pathology until a minor's behavior fits into the generally accepted cultural framework (Braht, 1994).

We have found out that insufficient flexibility of the behavioral ways of overcoming the life difficulties in minors staying at special institutions leads to the following maladjustment variant - poverty of diverse behavioral responses and permanent use of one and the same reactions, which from the standpoint of social standards is perceived as deviation (evasion) - a negative diversion from the behavior standards. The extent of such diversion is determined by deeds matching social expectations or not. A child is in the process of continuous growth and development which is seldom smooth. Destructive behavior and even antisocial (socially disapproved) actions are observed in children too often (Blackburn, 2002).

In the Russian research works, the deviant behavior is explained by mismatch of standard requirements with the requirements of life, on the one hand, and by mismatch of life requirements with the interests of a given personality, on the other hand. It is the controversy between stability and mobility of society as a system that acts here as the main point.

\section{Acknowledgements}

We express a special gratitude to A.G. Bernhardt, graduate of the clinical psychology chair of Surgut State University, who worked directly with this category of minors as a practicing psychologist, leader of the psychological project "Conflicts in our life".

\section{References}

Bandura, A. (2000). Teoriya sotsialnogo naucheniya [Theory of social learning]. SPb.

Blackburn, R. (2002). The Psychology of criminal conduct. N.Y.: John Wiley \& sons.

Blum, M. (1994). Profilaktika v sotsialnoy rabote [Prevention in social work]. Encyclopaedia of social work, Vol. 2, 369-375.

Braht, N. (1994) Profilaktika v zdravookhranenii [Prevention in health care]. Encyclopaedia of social work, Vol. 2, 365-369.

Dementieva, I.F. (2000). Sotsialnoe sirotstvo: ghenezis i profilaktika [Social orphanage: genesis and prevention]. M.

Gerasimov, S. (2002). Preduprezhdenie prestupnosti: teoriya, opyt, problemy [Crime prevention: theory, experience, problems]. Zakonnost', No. 2, 2-7.

Ghilinskiy, Ya.I. Sotsiologhiya deviantnogo povedeniya [Sociology of deviant behavior] / Ya.I. Ghilinskiy. - SPb.: SPbF RAN, 1993. - 217 p.

Khoziev, V.B. (2005). Oposredstvovanie v teorii i praktike kulturno-istoricheskoi kontseptsii [Mediation in theory and practice of culturalhistorical concept]. Retrieved from: http://psyjournals.ru/kip/2005/n1/Khoziev.shtml

Khoziev, V.B., Khozieva, M.V., Khokhlova, N.I. et al. (2014). Proektnaya forma obucheniya: opyt sozdaniya, issledovaniya i primeneniya [Project learning form: an experience of creation, research and application]. Surgut: IKC "SurGU".

Individual and typological questionnaire of L.N. Sobchik. Retrieved from: http://www.ht.ru/tests/bank/annrtf/ito.php

Levitt, M.J., Guacci-Franco, N., Levitt, J. (1993). Convoys of social support in childhood and early adolescence: structure and function. Developmental Psychology, V. 29, 811-818.

Lukin, S.E. Frustration test of S. Rosenzweig / S.E. Lukin, A.V. Suvorov; SPb.: Imaton, 1993. - 65 p.

Melnikova, E.B. (1966). Primenenie prinuditelnykh mer vospitatelnogo kharaktera $k$ nesovershennoletnim pravonarushitelyam [Applying compulsory measures of educational character to wrongdoing minors]. Sovetskoe gosudarstvo i pravo [Soviet state and law]. M.: Nauka, No. 4, 119-125.

Metody profilaktiki deviantnogo povedeniya [Methods of preventing the deviant behavior]. (1998). Samara: SamGPU publishing house. 
Moffitt, T.E., Caspi, A., Harrington, H., Milne, Males, B.J. (2002). On the life-course-persistent and adolescence-limited antisocial pathways: follow-up at age 26 years. Development \& Psychopathology, 14, 179-207.

Rodermel, T.A. (2014). Effektivnost' igrovykh tekhnologiy v rabote $s$ det'mi, imeyushchimi otkloneniya v povedenii [Efficiency of playing technologies in working with children having deviations in behavior]. Scientific miscellany, No. 1(1), $286-292$.

Soderzhanie i organizatsiya deyatelnosti tsentrov psikhologo-pedagogicheskoi pomoshchi naseleniyu [Content and organization of activity of psychologo-pedagogical assistance centers for the population]. (1997). M.: SRI of family.

Sotsialnaya profilaktika pravonarusheniy: sovety, rekomendatsii: prakticheskoe posobie [Social prevention of wrongdoings: advice, recommendations: practical guide]. (1990). M.

Washburn, J.J., Romero, E.G., Welty, L.J., Abram, K.M., Teplin, L.A., McClelland, G.M., Paskar, L.D. (2007). Development of Antisocial Personality Disorder in Detained Youth: The Predictive Value of Mental Disorders. Journal of Consulting and Clinical Psychology, 75(2), 221-231.

Zmanovskaya, E.V. (2003). Deviantologhiya (psikhologhiya otklonyayushchegosya povedeniya) [Deviantology (psychology of deviant behavior)]. M.: Akademiya. 